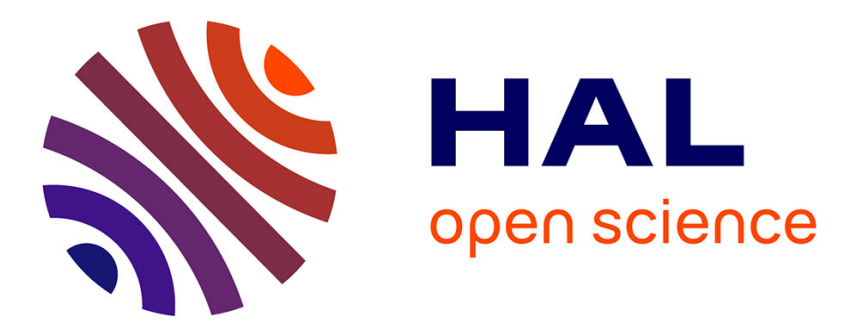

\title{
Sustainable agriculture issues explained by differentiation and structural coupling using social systems analysis \\ Egon Noe, Hugo F. Alrøe
}

\section{- To cite this version:}

Egon Noe, Hugo F. Alrøe. Sustainable agriculture issues explained by differentiation and structural coupling using social systems analysis. Agronomy for Sustainable Development, 2015, 35 (1), pp.133144. 10.1007/s13593-014-0243-4 . hal-01284262

\section{HAL Id: hal-01284262 \\ https://hal.science/hal-01284262}

Submitted on 7 Mar 2016

HAL is a multi-disciplinary open access archive for the deposit and dissemination of scientific research documents, whether they are published or not. The documents may come from teaching and research institutions in France or abroad, or from public or private research centers.
L'archive ouverte pluridisciplinaire HAL, est destinée au dépôt et à la diffusion de documents scientifiques de niveau recherche, publiés ou non, émanant des établissements d'enseignement et de recherche français ou étrangers, des laboratoires publics ou privés. 


\title{
Sustainable agriculture issues explained by differentiation and structural coupling using social systems analysis
}

\author{
Egon Noe • Hugo F. Alrøe
}

Accepted: 11 July 2014 / Published online: 1 August 2014

(C) INRA and Springer-Verlag France 2014

\begin{abstract}
In spite of many initiatives to increase sustainability, agriculture moves in the opposite direction with increased pesticide impacts and decreased nature quality. Here, we propose that this issue is not mainly due to lack of agronomic knowledge, but due to the lack of knowledge on social processes of specialization and differentiation. Here, we review the challenge of agriculture and sustainable development based on Niklas Luhmann theory of social systems. We focus on the concepts of differentiation and structural couplings. We use two forms of analysis, discursive differentiation and organizational differentiation, which mutually support each other. First, we analyze discourse categories, named 'semantics' in the social systems theory, such as 'environmental problems' and 'food safety'. We then look at how these discourses are related to the discourse of sustainability. Secondly, we describe different forms of organizational differentiation within agriculture and food, e.g., in the pig production chain. Here, we show how sustainability problems can be seen as an unavoidable consequence of the 'decouplings' that follow these differentiation and specialization processes. Finally, using the insights from social systems theory, we discuss how these sustainability problems might be mitigated by the following three forms of new structural couplings: (1) functional couplings of organizations to generalized semantic perspectives on e.g., environment and nature, which can reintroduce the sensibility of agri-food systems to their surroundings, (2) structural couplings between organizations that can handle other dimensions than price and quantity, including couplings mediated by labels and network couplings such as partnerships that provide options for co-evolution, and (3) second order couplings to polyocular semantics such as the
\end{abstract}

E. Noe $(\bowtie) \cdot$ H. F. Alrøe

Department of Agroecology, Aarhus University,

Postbox 50, 8830 Tjele, Denmark

e-mail: egon.noe@agrsci.dk sustainability semantic; that is, semantics that have their strength and challenge in the fact that they are multiperspectival and must remain indeterminate. Social systems analysis is a novel and strong tool to analyze social differentiation processes in agriculture. Social systems analysis provides researchers, farmers, and companies new ways to understand the sustainability problems that these differentiation processes produce.

Keywords Social systems · Differentiation - Structural coupling $\cdot$ Agriculture and food $\cdot$ Sustainable development

\section{Introduction}

Sustainability is one of the key concerns of modern society, and the development of sustainable agriculture in terms of food security, climate change, nature conservation, biodiversity, and long-term resilience is among the big challenges in the world (McDonagh 2014). In 2009, Lichtfouse et al. stated in this journal that the global goal of sustainable development is clear, but it is not very clear how we can understand and handle the specific problems and practical possibilities of sustainable development of agriculture. The situation has not improved much in this respect since then. In spite of many initiatives to increase sustainability, agriculture in many ways seems to move in the opposite direction (Marsden 2013; McDonagh 2014).

An example to illustrate this is the Danish implementation of the EU pesticide framework. Based on the ideas of ecological modernization (Murphy 2000), there was a belief that implementation of new technology and professionalization of farm management following the enlargement and specialization of farm enterprises would lead to a reduction of pesticide use. Therefore, the Danish implementation was formed as a voluntary agreement between the government and the farmer organization. However, despite the growth in farm size 
(Fig. 1), the agreed reduction of pesticide use has not been reached and the environmental impact of pesticides is growing (Fig. 2). We propose that this is not mainly due to lack of agronomic knowledge and dissemination (Noe et al. 2014), but due to fundamental social processes that influence both the way agriculture develops and the concepts that we use to grasp this development, including the semantics of sustainability. There are a range of different observation perspectives attached to sustainability, such as environment, nature quality, landscape, rural development, and food security, and there are different governmental and non-governmental bodies that represent these perspectives in the efforts to ensure a sustainable development in agriculture. However, in practice, it is difficult to get these perspectives to interact and to get a grip of sustainability problems.

In general, the complexity of transitions in agriculture requires that we go beyond agronomy in a narrow sense and include social science (Lamine and Bellon 2009). The German sociologist Niklas Luhmann provides a social science framework, which is well suited to illuminate this problem (Luhmann 1989). He asks how we can explain that modern society has special, acute problems with its environment and how society has changed, and states: "One useful hypothesis is that changes have to do with the form of societal system differentiation and with the increasing complexity it provokes" (Luhmann 2012: 75). The purpose of this article is to investigate how Luhmann's theory of social systems, and in particular the concepts of functional differentiation and structural coupling, can be used to analyze sustainability problems, to understand what leads to sustainability problems, and to form a basis for concrete tools to handle them.

\section{Methods}

In practice, the development of agri-food systems must be seen as a number of concurrent processes concerning both the specialization and differentiation of organizations and companies with regard to their tasks and operations and the emergence and differentiation of new thematic semantics, discourses, or perspectives in society. These two kinds of processes are not independent, they interact and intertwine. In order to observe this development, we apply Luhmann's theory of social systems e.g., Luhmann (1995, 2012, 2013a, b), a highly elaborated, comprehensive, and detailed theory of social systems as autopoietic communicative systems.

\subsection{Social systems theory}

The basic aspect of social systems for Luhmann is communication. He distinguishes between three kinds of social systems: interaction systems (short-lived systems of conversation), organizational systems (systems that reproduce themselves through decisions such as companies and NGOs), and the functional subsystems of society (systems based on specialized semantic domains such as law and economy) (Luhmann 1995: 2ff).

“... 'society' signifies the all encompassing social system of mutually referring communications. It originates through communicative acts alone and differentiates itself from an environment of other kinds of systems through the continual reproduction of communication by communication. In this way complexity is constituted through evolution." (Luhmann 1989: 7).

\subsubsection{Autopoiesis and closure}

Luhmann's theory of social systems is based on the theory of biological organization developed by Maturana and Varela $(1980,1987)$. The central idea of Maturana and Varela is that biological organisms are open for material flow, but organizationally closed and self-referential, that is, they are autopoietic. It is the organism itself that constructs its own components and reproduces its own organization. That the autopoietic system is self-referential means that every input for organization is produced by the system itself. The key thesis of autopoietic systems is thus that they are operationally closed. Operational closure means that the system relies entirely on internal operations; its operations always take place within the system itself (Luhmann 2013b: 64).

Luhmann took the fundamental process of Maturana and Varela's autopoiesis - the systems reproduction of its basic elements to preserve its own organization - and applied it to social systems in the form of self-production of the communicative elements. Luhmann thus defines a social system as the difference between the system and its environment; the communicative system itself determines what belongs to the system and what belongs to its environment.

"Autopoietic systems are systems that are defined as unities as networks of production of components that recursively, through their interactions, generate and realize the network that produces them and constitute, in the space in which they exist, the boundaries of the network as components that participate in the realization of the network." (Luhmann 1990: 3).

\subsubsection{Irritation and resonance}

Seeing social systems as autopoietic or self-organizing means that the environment cannot determine changes in the system. Influences from the environment can only be irritations, and it is the ability of the system to become irritated that determines its reaction to them. 
Fig 1 Development in farm size in Denmark 1982-2012, shown as the share of land farmed by different farm sizes (source:

Statistic Denmark)

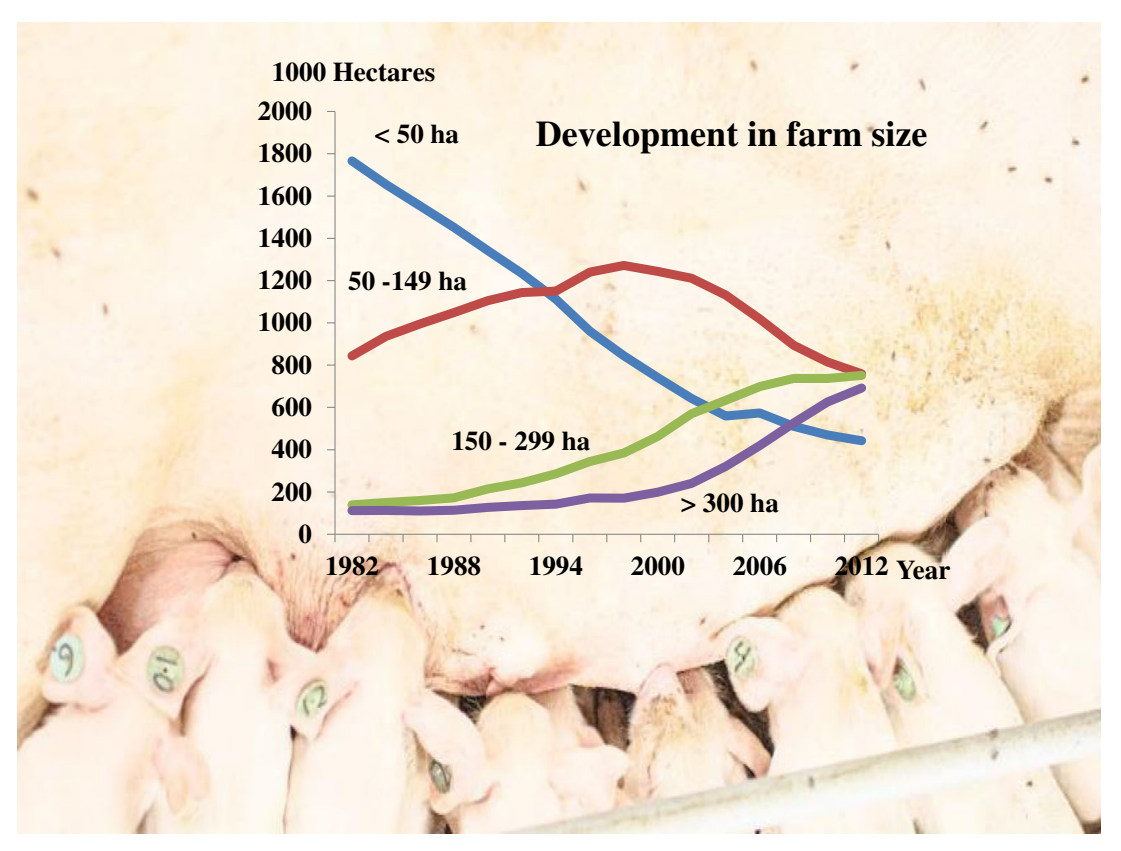

\subsubsection{Complexity and differentiation}

The autopoietic reproduction and operational closure of communicative systems cause society to develop its own structural complexity (Luhmann 2012: 77).

“... complex systems like societies are differentiated into subsystems that treat other social domains as their (socially internal) environment, i.e., differentiate themselves within the society, for example, as a legally ordered political system that can treat the economy,
Fig 2 Pesticide treatment frequency (BH) 1997-2012 and impact of pesticides on environment and health (PBI) 2007-2012 in Denmark (source: Bekæmpelsesmiddelstatistik 2012)

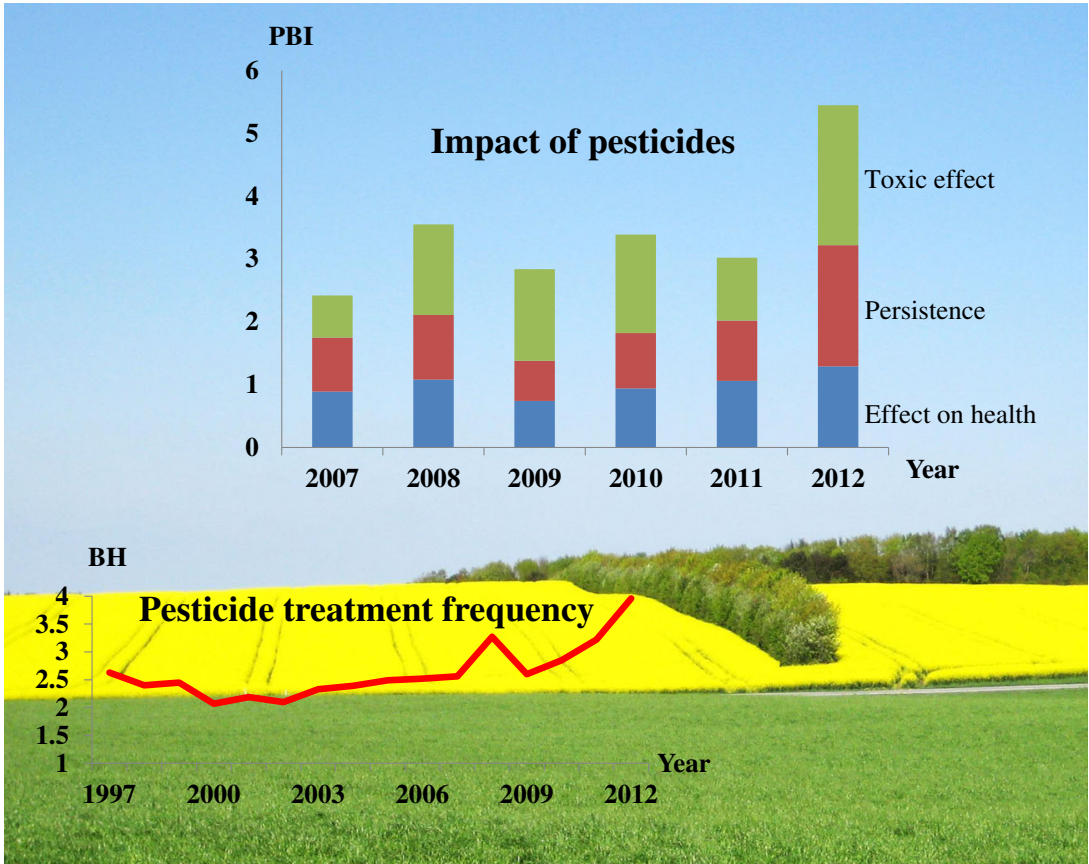


science, etc. as environment and thereby relieve itself of direct political responsibility for their operations. This differentiation theorem has far-reaching consequences." (Luhmann 1989: 19).

Societal system differentiation provokes increasing complexity; functional differentiation means above all the operational closure of functional systems too, and subsystems assume universal competence for their specific function, vastly increasing the functional capacity available for organizational systems (Luhmann 2012: 75). The notions of complexity and differentiation in social systems theory are therefore pivotal to analyzing and understanding sustainability problems.

Complexity is a complex concept. Luhmann often states that the environment is always more complex than the system (e.g., Luhmann 1995: 182). This is in line with the first attempts to formulate a general systems theory in the 1950s and 1960s, where complexity was the central problem as an obstacle for rational planning (Luhmann 2013b: 120ff). Since the system was seen as part of the world, this led to the question of how a system can deal with a more complex environment, or reduce complexity, since it does not have the requisite variety to create a correspondence with the environment.

In autopoietic systems theory, the viewpoint is radically shifted to the systems point of view, as an observing system, and the complexity of the world as such becomes meaningless; it is moved beyond the horizon of observation. Only as second order observation are we able to take up the question of complexity again (Alrøe and Noe 2012: 44ff, Luhmann 2013b: 131).

The notion of self-reference also leads to the understanding that it is the internal complexity of the system that is limiting the capability of the system to observe itself and the capability to observe the encompassing world. This is in line with the biosemiotic understanding that each biological species has its own subjective or phenomenal world in the tradition of Jakob von Uexküll (1982). According to Uexküll, the complexity of the environment is conditioned on the complexity of the system more complex organisms have more complex environments and the environment is always less complex than the system.

Various descriptions of complexity are possible depending on how the observer resolves the unity of a manifold into elements and relations, a system can describe itself as complex in various ways, and an observer can describe the complexity descriptions of another observer so that hyper-complex systems can come into being that also contain a plurality of complexity descriptions (Luhmann 2012: 80). We therefore must abandon the idea that complexity can be simplified and instead ask how complexity is observed using the methodology of second order observation (Luhmann 2012: 83).

Speaking of complexity, we need to distinguish between complexity from the perspective of an outside observer, where the world outside the system is obviously much more complex than the environment, and complexity from the inside perspective of the system, where the environment is always less complex than the system (Alrøe and Noe 2012). Only from an outside perspective can the development of the complexity of the system be discussed in relation to the complexity of the environment, and it is possible to speak of the system's indifference to its environment (or ignorance of the environment).

Luhmann states that evolutionary advances reduce complexity in order to organize greater complexity on the basis of this restriction (which is a paradox as stated), and he mentions agriculture as an example of an area in society where strategically crucial evolutionary advances enable greater complexity (Luhmann 2012: 306). We agree, but in our analyses we overcome this paradox by specifying that the complexity is reduced from an inside perspective and increased from an outside perspective.

\subsubsection{Semantics and functional systems}

In Luhmann's theory of society, modern society consists of functional subsystems, such as economy, law, politics, science, art, religion, etc. These functional systems have evolved from the communications and semantics of society into autopoietic (self-creating) communicative systems, which provide society with specialized perspectives with special codes, semantics, and generalized media; perspectives with which society can observe itself. Luhmann's concept of semantics expresses condensed modes of expression in language, with which society reproduces meaning that is worth conserving (Luhmann 2012: 188). Luhmann speaks of different semantics (of love, organizational theory, etc.) in the same way that different discourses are used in the tradition of Foucault (e.g., Fleming and Vanclay 2010). But whereas a discourse can contain characteristics of a system in Foucault, only systems hold the characteristics of a system, and systems employ semantics, in Luhmann (Andersen 2003: 86). Semantics are condensed and repeatable forms of meaning that are at our disposal for communication, but semantics do not conflict like discourses can. However, there is an intricate relation between the evolutionary development of semantics and of society, and between system differentiation and semantic differentiation (Luhmann 2012: 325-327, 172). Luhmann's theory thereby poses the questions of (1) when a semantic has developed into, or spurred, a function system proper, with the closure and autonomy that comes with it; and (2) how semantics and systems relate to each other historically and today.

\subsubsection{Structural coupling}

A structural coupling is "the specific form in which the system presupposes specific states or changes in its environment and relies on them" (Luhmann 1991: 1432). Over time, the system may change its structures of expectation and thereby establish 
structural couplings with its environment, corresponding to the classical ideas of learning and adaptation. Structural couplings thus reduce and facilitate the influence of the environment on the system.

Structural couplings are permanent and stable couplings in contrast to the looser temporary operational couplings that constantly take place in a system's autopoiesis and relation to its environment. The concept was originally used by Maturana and Varela (1981) to describe the correspondence with the environment that living systems depend on for their survival. Luhmann has generalized the concept to designate couplings between different types of autopoietic social systems, i.e., between organizational systems such as the parties of agri-food chains, between functional systems such as the economic system and political system, and between organizational systems and functional systems.

\subsection{Strategies of analysis}

Luhmann's theory has the distinct advantage that it includes a theoretical basis for both semantic and organizational analysis. Consequently, we employ two separate strategies of analysis, which mutually support each other. Firstly, we make a semantic analysis of the kinds of semantics that have differentiated in and around agriculture. In our analysis of agricultural development, we focus on the semantics that have differentiated into clearly identifiable semantics that structure the communications around agriculture and food, and which are interrelated with the organizational differentiation, but which have not developed into well-established functional subsystems of society (cf. Andersen 2003: 89). Our categories for the semantic analysis are based on Lars Qvortrup's (2003: 149) table of functionally differentiated subsystems in society, where he operates with the code, rationale, function, program, and institutionalization (see also Luhmann 1989: 45 on the distinction between code and program). Secondly, we describe different forms of operational specialization and differentiation of organization systems within agriculture and food, and examine the communicative "decouplings" that follow from these differentiation processes and how they may lead to sustainability problems. Finally, we use the two analytical approaches to discuss how these sustainability problems might be mitigated by new structural couplings between the specialized systems.

Throughout the organizational differentiation analyses, we use Danish agri-food chains as the main case, a case with which we are intimately familiar. The differentiation processes in different industrialized countries look somewhat different, but the overall trends and conclusions are the same. The Danish case therefore serves both as a concrete illustration of these rather abstract social science analyses that makes them easier to understand, and as a case that is more or less representative for the development of agriculture and food in industrialized countries.

\section{Results and discussion}

3.1 The differentiation of semantics in the field of agriculture and food

In the communication of society, a multitude of themes emerge and separate, and some differentiate into distinct perspectives for observation and connected social semantics. These semantics can in time become institutionalized into specialized functional systems such as economy, law, and science (Luhmann 1995). In this section, we analyze some of the key semantics that have emerged and become institutionalized in the field of agriculture and food, or which are of decisive importance for this field. In Table 1, we have listed some of the most important semantics around agriculture and food, based on Lars Ovortrup's (2003: 149) table of functionally differentiated subsystems in society. Apart from Qvortrup's categories, we added a category on irritation as a way of describing the sort of differences that were decisive in the historic differentiation of these semantics and observation perspectives.

This process of creation and differentiation of new semantics has a long history. Some semantics have their roots far back, while others are quite new, and some have arisen and declined. We have attempted to list them in the historical order that they unfolded and closed themselves as independent semantics. In Denmark, for example, the nutrition semantic was institutionalized in the form of the State household council "Statens Husholdningsråd" in 1935, while the climate change semantic only really manifested itself in the 1990s. The individual semantics are also dynamic. If we take the nutrition semantic again, this was originally about avoiding malnutrition, getting the right diet, and this was enforced during the first and second world war. But slowly, the focus of the semantic has changed to also include obesity and other lifestyle diseases. A semantic can develop into an independent observational perspective, and some semantics have historically developed into functional systems proper, such as economics, with their own symbolically generalized media, such as money (Luhmann 2012: 190ff). Most of the semantics in table 1 have been institutionalized to such a degree that they serve as a form of generalized media. One can, for instance, trade in carbon credits, and environmental labels serve as a media in the relation between supermarkets and consumers.

These semantics have developed into specialized perspectives on agriculture and food production; specific perspectives that are used in both research and policy. However, the autopoietic and systems theoretical understanding shows that the differentiation and specialization of the semantics is connected to a reduction in the complexity of their environment, in what the perspectives can observe. This means that each perspective becomes blind to aspects that can be observed with other perspectives. 


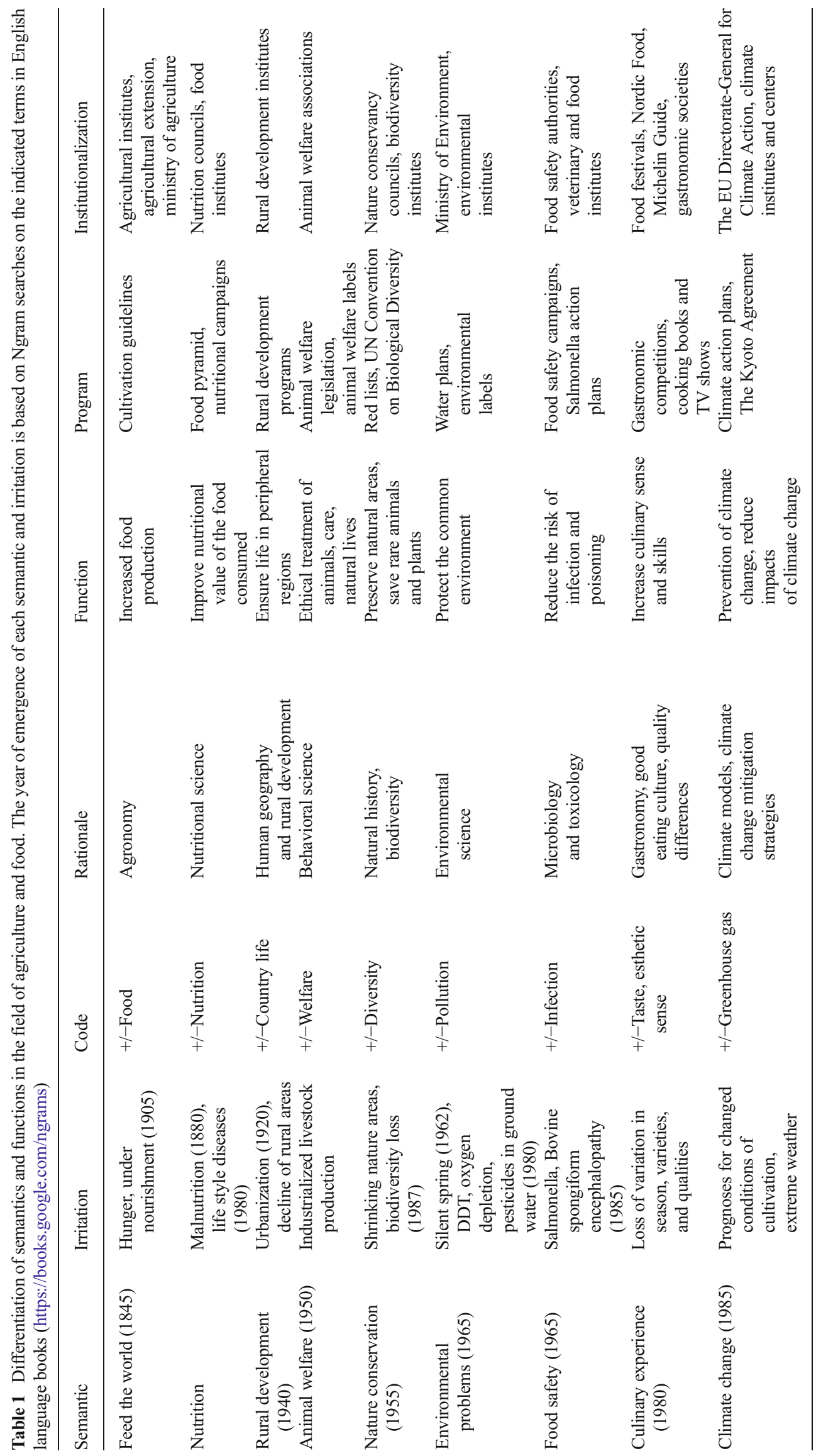


There is a key semantic that is not included in Table 1, namely sustainability, which emerged around 1980. This is because sustainability is attached to what we call a paradoxical observation perspective, in the sense that this semantic so to speak wishes to take the whole into consideration. Since this is not possible, the semantic of sustainability has to connect to a multitude of specialized perspectives, and therefore cannot obtain closure like a functional system proper, but has to remain indeterminate. Later, we will return to the importance of this key condition for sustainability problems, but first we will look at the relation between these problems and the organizational development of agriculture.

\subsection{Specialization and differentiation of organization systems}

In the second part of our analysis, we look at the operational differentiation of specialized organization systems within agri-food chains. There are at least three major parallel historical developments which are mutually conditional, but which is analytically appropriate to separate:

1. Vertical differentiation into more links of the food chain

2. Horizontal differentiation into separate branches of agricultural production

3. The differentiation of family farms into business and family life

\subsubsection{Vertical differentiation-from field to table}

Vertical specialization and differentiation can be described as two interconnected processes. One process is the genesis of more links in the chain. Take for instance the production of pork, where piglets and fattening of pigs have increasingly become divided into two different organizational farming systems, selling and buying piglets at market prices, and the slaughtering of pigs and processing of pork have been separated into two or more different independent organizational systems.

The other process is the reduction of structural couplings. In the first phase of differentiation, many structural couplings in terms of reciprocal agreements and dependency were formed, to compensate for the reduction of complexity - as we for instance find it in the first phase of the cooperative dairies where the dairies were obliged to process and sell the delivered milk at the best price for the farmers. Gradually, these dairies closed themselves more and more around their own business logic with an increasingly market-based connection with the farmers. Today, the Danish cooperatives are to a much greater extent hybrid forms between a cooperative and a joint-stock company, which also buy raw materials for processing at the bulk market. In particular, this development is seen on the supply side where the (former) cooperative suppliers have decoupled almost completely and prizes and conditions are negotiated in the individual purchase situation. This means that members of the cooperative are no longer necessarily treated in the same way. These organizational developments mean that each organization can increasingly concentrate on optimizing its own operations. However, the price of this decoupling is that the mutual loyalty of the members (the other links in the chain) diminishes.

\subsubsection{Horizontal differentiation-specialization}

While there has been a long historical process of vertical differentiation within agriculture, horizontal differentiation, in particular at the level of primary production, is of relatively newer date. Until 1960, almost all farms holdings in Denmark were mixed farming systems with a balanced production between plant, cattle, pig, and poultry production. Fodder for the livestock was produced on the farm, fields were used for grazing, and manure from the livestock production was spread on the fields of the farm. A number of simultaneous developments, including mechanization and the development of agrochemical components, made a horizontal differentiation possible. For example, the capital stock of machinery more than doubled in Denmark from 1960 to 1975 (Behrens and de Haen 1980), and agricultural output per worker doubled from 1960 to 1970 (Yamada and Ruttan 1980), with similar trends, despite differences, in other European countries. Within a decade, there was an extensive specialization and differentiation in different production branches, and the mutual bindings or structural couplings between the different productions branches diminished. Simultaneously, the professional and political organizations in the fields of pigs, cattle, poultry, eggs, and plant breeding evolved as independent organizations.

If we look again at pig production, there was at first an internal differentiation between plant production and meat production at the farm, and gradually the two operations became more independent of each other and increasingly driven by different optimization rationales. The main purpose of the plant production was now not necessarily to feed the pigs, and the pig production did not necessarily have to adjust to the productivity of the plant production. However, the Danish legislation has maintained a structural linkage in the form of farmland requirements associated with livestock production, which establishes a maximum number of livestock units per hectare. In recent years, there have been various approaches to decouple these bindings between land and livestock production as well, through measures such as biogas production and burning of livestock manure so that pig production to a higher degree obtains the same conditions as other industrial productions. 


\subsubsection{Differentiation of farming and family life}

Differentiation of family farms into business and family life is the last form of organizational differentiation in this analysis. Agricultural production is increasingly decoupled from family life and the operational logic is thus changed to that of an independent company. In Denmark, this differentiation of family life happened almost parallel with the specialization processes described above, but slightly delayed. There are a number of conditions (irritations) in the encompassing world which enable and stimulate this differentiation process. Again, mechanization has been a major factor; among others things, it has made the farm wife free from heavy household obligations and freed (or forced) her to take up work outside the holding, and it has made the working hours at the farm more and more comparable to ordinary industrial working conditions. This means that family life to a lesser extent is organized around the concerns of the production and farm operations. Another dimension of this differentiation and decoupling process is the marginalization of generational succession as a key perspective, so that decisions are no longer determined by the handover of the farm to the next generation. We have in particular seen this in Denmark, where one of the major irritations stimulating this development was the strong structural development, leading to a reduction in the number of full-time farm holdings of around $10 \%$ per year since 1960 .

This exclusion of the family life and successor perspectives has meant that the individual farming business now to a much larger degree is able to close its operations around a more short-sighted production and investment logic that aims to achieve the best return on the capital and labor invested in the production. This is also reflected in the fact that many agricultural holdings change their organizational form from family farms to partnerships or Ltd.

\subsection{Reduction, decoupling, and sustainability problems}

The semantic and functional differentiation that was treated in section 3.1 and the organizational differentiation in 3.2 are synchronic and interdependent processes. The driving force behind these processes is a reduction of the complexity that the system must relate to. Reduction of complexity in the individual organizational systems (through differentiation and specialization) forms the basis for the ability for agriculture to handle an increased complexity overall. The complexity is thus reduced only from an internal systems perspective, and therefore the German "ausgrenzen," which does not have an English equivalent but means roughly "to limit out" or "put outside the border," may be a better overall term. The three forms of differentiation of organizational systems within agriculture and food that were identified in the previous section, are based on different forms of reduction of complexity in systems operations:
1. Reduction in the complexity of consecutive operations (vertically)

2. Reduction in the complexity of parallel operations (horizontal)

3. Reduction in the complexity of meaning, considerations, and objectives

As described above, these three movements in terms of reduction of complexity free the focus of the production systems to optimize internal operations. It frees piglet producers to become more and more efficient in producing piglets, dairy farmers to produce more and more kilos of milk from each cow, the abattoirs to reduce the costs of slaughtering a pig, etc. This increase in efficiency can be seen very clearly in the increase in productivity that has happened over the last 50 years. However, simultaneously with this reduction of the internal complexity, these organizational systems also reduce the complexity of their phenomenal world (cf. Alrøe and Noe 2012), i.e., the systems reduce the types of differences in the encompassing world that are allowed to irritate them (and at the same time increase what they can be irritated by within their area of specialization), and there is an increasing degree of decoupling.

The first, vertical form of reduction and differentiation into more links in the chain, means that the farm businesses less and less have to worry about what consumers think. Their phenomenal world is the processors and who pays the highest price for the produce. It also means that the consumers generally care less and less about what actually happens in the primary production. The phenomenal world of the consumers is increasingly reduced to the supermarket. The vertical differentiation therefore makes it increasingly possible to decouple sustainability aspects, like how the products are produced and what the external effects of production are, from the market relations. This reduction in structural couplings decreases the options for feedback mechanisms that could secure a long-term sustainable development of food production.

The second, horizontal form of reduction and differentiation into parallel production branches, means for example that pork production systems no longer have to worry about soil fertility and sustainable production of animal feed. The development within the agrochemical industry means that arable farming systems no longer (at least in the short term) have to worry about the crop rotation-related problems with weeds and pests, or worry about the availability of nutrients in the soil. Recycling of nutrients is often much more cumbersome and harder to control than the use of inorganic fertilizers. The horizontal differentiation allows a decoupling from processes like recirculation of nutrients and organic material and crop rotations that are to avoid pest and weeds and increase soil fertility; processes that are of central importance for the longterm sustainability of agricultural production. 
The third form of reduction and differentiation into business and family life means that agricultural production systems do not necessarily allow themselves any longer to be irritated by the succession problem and thereby the long-term perspective of the family farm, which makes the businesses more flexible to focus their decisions on what the best return of capital is in the short run. This may lead to a decoupling from concerns about the long-term sustainability of the farming practice.

These are just some examples of the reductions in the environmental complexity of the systems that these differentiation processes entail, and thus the reduction of possible irritations that the individual agricultural activity can react on in relation to the internal organization and management of the system; in other words, a reduction in resonance capacity. A logical consequence of these differentiation processes is that the agricultural praxis is generally moving away from a position that can handle the plurality of perspectives involved in the semantics of sustainability; and away from a condition where they are sensitive to irritations that are expressions of the various dimensions of sustainability. An example to illustrate this problem is the decomposition of humus in agricultural soil as a result of monocropping and heavy mechanical treatment of the soil, resulting in a loss of carbon in the form of greenhouse gas emissions that contribute to global warming. The humus content of the soil is crucial for the natural fertility of the soil, but the agrochemical components in terms of fertilizers and micronutrients makes a decoupling from the soil fertility possible, and allows farm enterprises to not be irritated by changes in the humus content and therefore not to include these concerns in the decisions of internal operations. Only if the greenhouse gas emission is reintroduced as an irritation in terms of economical means or legislative means can the concerns of the humus contents be reintroduced in the operations of the systems.

\subsection{Three types of re- and new-couplings to handle sustainability problems}

From a Luhmannian systems theoretical analytical approach, we have shown that sustainability problems can be seen as a more or less unavoidable product of the processes of differentiation, specialization, and decoupling which takes place within agricultural production and food chains. The semantic and functional differentiation of perspectives on food production has increased the overall complexity of sustainable food production. The answer to this increased overall complexity has been an organizational differentiation and specialization of the systems in the agri-food chain, where each system in the chain, whether it is a farm, a processing company, or a retailer, only focuses on what is of main importance of the operation of the organizational system. This development moves us further and further away from a situation where any of the involved perspectives can observe the complexity of sustainable development of agriculture and food, and where any of the involved organizational systems can handle the overall complexity of sustainable agriculture and food production. It is therefore relevant to investigate the possibilities for recoupling and new-coupling to sustainability concerns, and whether such new structural couplings can help to manage sustainability problems.

In the first part of our analysis (section 3.1), we examined some of the semantics that have developed co-evolutionary with the organizational processes of specialization and differentiation. Some of these semantics and generalized media, in particular economic efficiency, have formed the basis for these complexity reduction processes. Other semantics, such as environment and landscape, have emerged as irritations resulting from these differentiation processes, and these semantics are often referred to in relation to the concept of sustainability. Since the overall complexity of society is increasing, the sustainability problems cannot be resolved by a return to a former, more ideal state. A systems theoretical approach to deal with sustainability problems will be to seek to reintroduce the various concerns in the form of re-couplings between the systems, that is, in the form of new structural couplings. In the following, we examine how these recouplings and new-couplings can be obtained in practice through an examination of a series of examples of various initiatives. We divide these initiatives into three types according to the kind of structural linkage:

1. Functional couplings: The coupling of an organizational system to generalized semantic perspectives or functional subsystems in society

2. Organizational couplings: Structural couplings between organizational systems

(a) Mediated couplings: Couplings mediated by labels

(b) Network couplings: Couplings that are reproduced within the food chain

3. Second order couplings: The coupling of an organizational system to a polyocular semantic

\subsubsection{Functional couplings}

An example of the first type, functional couplings, where a farming enterprise is striving to reintroduce a sensitivity to the outside world by re-coupling to generalized semantic perspectives, is "Ethical accounting for livestock farming" (Jensen and Sørensen 1998), which built on ideas from the "Ethical accounting" developed by Pruzan and Thyssen (1994) However, in contrast to the "Ethical accounting", which is based on discourse ethics, "Ethical accounting for livestock 
farming" attempted to establish various objectified perspectives. Animal welfare was, for example, measured by a mixture of registrations of physical conditions, such as space for the individual cow, and objective states of conditions in the form of absence of illnesses and injuries and various tests of anxiety reactions of individual animals; and the environmental state was included in the form of nutrient and energy balancing accounts for the holdings. The underlying idea of this approach is thus that each agricultural holding, as an iterative process, must be able to follow the development in how the farming practice affects the encompassing world in the various dimensions included in the accounting system, referring to the different semantics linked to the sustainability debate. In its original form, the "Ethical Account for livestock farming" has not been widely implemented in Denmark, but there are elements of it that are prevalent in e.g., "Green accounting," where options for the farms to observe environmental and nature issues are in focus (Halberg et al. 2005). Another example of such intra-organizational functional coupling is the concept of "Good Agricultural Practice", a set of voluntary guidelines developed by the Farmers Unions in Denmark (see also the more institutionalized concept of Good Agricultural Practices developed by FAO, http://www. fao.org/prods/gap). Here, the main aim is to reintroduce different considerations into operational management, which are not based on pure economic reasoning, but draw on references to e.g., pride and craftsmanship, and include considerations of values and concerns for employees, neighbors, consumers, livestock welfare, nature, landscape, and environment.

\subsubsection{Organizational couplings}

The second type of re-couplings, organizational couplings, can be divided into two forms, mediated and network couplings. Mediated couplings are structural couplings between organization systems which are mediated by generalized media such as labels. Examples from animal welfare are the label "Recommended by the Animal Protection Association" in Denmark (e.g., http://www.dyrenesbeskyttelse.dk/anbefaletaf-dyrenes-beskyttelse), RSPCA's Freedom Food scheme in the UK (http://www.rspca.org.uk/freedomfood), and the broader Label Rouge quality label in France (http://www. labelrouge.fr). Examples from the environmental semantic is the Nordic "Swan label" (http://www.nordic-ecolabel.org) and the European "Flower label" (http://www.ecolabel.eu), both guaranteeing that the labelled product is the least burdensome within its category, takes into account your health, and is of good quality. Organic labels such as the Danish red " $\varnothing$ " label also belong to this category. But, as we will elaborate later, the $\varnothing$ label is not anchored in a single semantic from table 1 , but is in itself a coupling between many semantics, including environment, animal welfare, health, social justice, fair trade, etc.

Common to the mediated couplings are, firstly, that they are dependent on generalized media, materialized in form of labels, and thus on the underlying functional systems and semantics. Without continued communication about, for example, livestock welfare and without an institutionalization in the form of e.g., animal protection associations, the label would no longer have a communicative value - the distinction would loose its meaning and importance.

Secondly, the individual organizational system is dependent on stable coupling possibilities. Take for example the $\varnothing$ label, where the organic food network around e.g., milk depends on stable reciprocal opportunities for structural couplings. In primary production, the farmer must abide by rules and control that make labelling with the $\varnothing$ label possible. The dairy must be able to handle the organic milk separately, process it in accordance with organic rules and guidelines, and pay a higher price for the milk to the farmer. The supermarket must be able and willing to make shelf space and placing available for the marketing of organic products. The consumer must be able to acknowledge the values and differences the $\varnothing$ label offers compared to conventional milk, and to buy the more expensive organic milk. These reciprocal opportunities for couplings can have more or less complexity-reducing features. For example, the structural link between the organic milk producer and the big dairy Arla is mutually contractually bound, so that the farmer is obliged not to sell organic milk to other dairies than Arla, and Arla is obliged to buy milk at a stipulated, higher price in relation to price of conventional milk.

This leads to the other form of organizational couplings, network couplings, which not only makes use of generalized media, but, so to speak, creates its own band width for communication between the organizations in the chain. An example is the increasing numbers of alternative food networks; networks that may well refer to generalized semantics, but also develop an internal semantic about the differences between inside and outside the network as a basis for coupling along the chain (Noe and Alrøe 2011). An example of such networks are the Danish Food Communities and the French AMAPS, which are consumer-driven food supply networks, where the network directly negotiates price, quality, and supply with the involved farm enterprises, and where a series of mutual expectations and ties makes these continued negotiations possible. Another example is that of more formalized partnerships between companies as "second order" agreements which are contracts about contracts or promises of later promises (cf. Andersen 2008), such as the long-term partnership between the organic dairy Thise and the supermarket chain Irma in Denmark. 


\subsubsection{Second order couplings}

The third type of new structural couplings, which we call second order couplings, is couplings to a polyocular semantic. As we stated in section 3.1, sustainability is a paradoxical observation perspective, in the sense that it seeks to take the whole into consideration, but has to rely on a multitude of specialized perspectives and remain indeterminate and open to new perspectives and sustainability concerns. To establish itself as a functioning semantic, sustainability therefore has to take the form of a multiperspectival or polyocular semantic (cf. Noe et al. 2008). A polyocular semantic is a second order perspective, based on observations of the observations of different specialized perspectives, which is able to take their restricted focus and blind spots into account and include this in the communication. Second orders couplings to a polyocular semantic such as sustainability, is thus a way for organizational systems to deal with the paradox of taking a holistic perspective. And second order couplings differ from the functional couplings in section 3.4.1 in that they are not couplings to a single and closed semantic perspective, but to a polyocular perspective that remains open, and which therefore continually irritates the organizational system to increased reflexivity.

Organics is an example of a polyocular semantic because organics like sustainability seeks to take the whole into consideration. But in contrast to the semantic of sustainability, the organic semantic has established and closed itself operationally in terms of the organic label as a generalized media accompanied by underlying rules. (In Denmark the organic $\varnothing$ label is the only organic label, and it is controlled by the Danish state.) But at the same time, this closure paradoxically contradicts the desire for a holistic approach that is at the core of the organic semantic. The organic label does not in itself constitute a perspective. You cannot tell whether an agricultural holding is more or less organic, without elaborating this via couplings with other generalized perspectives, such as whether it is more environmentally friendly, healthier, tastes better, or whatever. The difference between organic/not organic is both determined by the organic label and must at the same time remain indeterminate. This indeterminateness shows up in the continued efforts within the organic organizations to develop new rules and principles for organic farming (e.g., Luttikholt 2007), and the fight against the reduction of organic farming to merely being an expression of the current rules (Alrøe and Noe 2008).

Sustainability at large is not easily differentiated to a functional system and a generalized media, although it is often used as such in structural couplings between, for example research system and the research grant bodies, where the notion of sustainability is often reciprocally expected to be included in the overall objectives of the research proposal. The concept of sustainability is often used as a buzz word to connect to current trends without any deeper meaning, and there are many competing semantics struggling to obtain hegemony over the concept (e.g., Alrøe and Glover 2006). The analysis here goes deeper in pointing out the paradoxical character of the semantic of sustainability, in line with Thompson's (2007) notion of the "paradox of sustainability" that arises because substantive, research-based approaches to sustainability may be too complex to effectively motivate appropriate social responses.

But rather than seeing this paradox, that the semantics of sustainability cannot offer a generalized media for structural couplings, as a problem, we can from a Luhmannian perspective argue that it is precisely the potential strength of the sustainability semantic, that it can only maintain itself as a polyocular semantic, whose input is observations of observations. Only by maintaining this hyper complexity, the hyper sensitivity in relation to the encompassing world can be maintained. If the semantic of sustainability should succumb to the temptation to be institutionalized as a functional system, for instance by way of establishing a fixed indexation system (e.g., in the form of an indicator system) that sums up to a single relative or absolute sustainability scale, the semantic will stiffen and thereby also loose the value and contents of the indicators, and the value as a media for structural coupling. This paradox is one of the main challenges in projects that aim to develop assessment tools to be used as generalized media based on "holistic" semantics such as sustainability and organics (Alrøe and Noe 2011). In the Core Organic project HealthyGrowth, involving ten European partners, we are looking deeper into the challenges of organizing organic value-based food networks on the polyocular semantic of organic agriculture.

\section{Conclusions}

Based on a Luhmannian systems analysis, sustainability problems within agriculture and food are a product of the differentiation processes, specializations, reductions and decouplings that take place, and the fact that the general development of society moves away from observation perspectives that can handle the complexity connected to the problem of ensuring a sustainable development.

In a still more complex society, reduction (ausgrenzen) of complexity is necessary for the development of social systems, but how the reduction happens is contingent. In relation to agriculture and agri-food chains, we see this development both in the form of differentiation of semantics, observation perspectives and functional systems, and in the form of horizontal and vertical differentiation and specialization of organizational systems. A logical consequence of this is that the phenomenal world of the individual organization (that is, the world that it can be irritated by) is simplified, and that the system is thereby decoupled from its surroundings (that is, the world that it is a part of) and options for resonance are lost. 
The greater efficiency of the individual system combined with a lesser sensitivity in relation to the surrounding world that the system affects, has increasingly given rise to concerns about the sustainability of this development, and a number of semantics about the relationship between the agricultural systems and their surroundings have emerged.

With reference to a number of present initiatives and movements, we have analyzed the opportunities for structural (re)coupling that can help reintroduce the options for the systems to be irritated by changes in their surroundings. We distinguish three forms of potential new structural couplings: (1) functional couplings of organizations to generalized semantic perspectives such as environment and animal welfare, which can reintroduce the sensibility of e.g., farm enterprises to their surroundings, (2) structural couplings between organizations that can handle other dimensions than price and quantity, including both couplings mediated by media such as labels and network couplings such as partnerships that provide options for co-evolution, and (3) second order couplings to polyocular semantics such as the sustainability semantic; semantics that have their strength and challenge in the fact that they are multiperspectival and must remain indeterminate.

This novel social systems analysis of agriculture shows that Luhmann's concept of structural couplings is not only a strong tool to analyze development processes in agriculture, but also a basis for understanding and handling the sustainability problems that the organizational and functional differentiation processes produce.

\section{References}

Alrøe BJ, Glover L (2006) Ecological justice and organic agriculture: ethics and practice. In: Halberg N, Alrøe HF, Knudsen MT, Kristensen ES (eds) Global development of organic agriculture: challenges and prospects. CABI Publishing, Wallingford, UK, pp 75-112

Alrøe HF, Noe E (2008) What makes organic agriculture move - protest, meaning or market? A polyocular approach to the dynamics and governance of organic agriculture. Agric Resour Gov Ecol 7(1/2):522. doi:10.1504/IJARGE.2008.016976

Alrøe HF, Noe E (2011) A cross-disciplinary approach to multicriteria assessment and communication of the effects of organic food systems. Proc Third Sci Conf ISOFAR 2:313-316

Alrøe HF, Noe E (2012) Observing environments. Constructivist Foundations 8 (1): 39-62: Available at http://www.univie.ac.at/ constructivism/journal/8/1/039.alroe

Andersen NÅ (2003) Discursive analytical strategies: understanding Foucault, Koselleck, Laclau. The Policy Press, Bristol, Luhmann

Andersen NÅ (2008) Partnerships: machines of possibility. The Policy Press, Bristol

Behrens R, de Haen H (1980) Aggregate factor input and productivity in agriculture: a comparison for the EC-member countries, 1963-76. Eur Rev Agric Econ 7:109-146

Fleming A, Vanclay F (2010) Farmer responses to climate change and sustainable agriculture. A review. Agron Sustain Dev 30:11-19. doi: 10.1051/agro:2009028
Halberg N, Verschuur G, Goodlass G (2005) Farm level environmental indicators; are they useful? An overview of green accounting systems for European farms. Agric Ecosyst Environ 105:195-212. doi: 10.1016/j.agee.2004.04.003

Jensen KK, Sørensen JT (1998) The idea of "ethical accounting" for a livestock farm. J Agric Environ Ethics 11(2):85-100. doi:10.1023/ A:1009519131191

Lamine C, Bellon S (2009) Conversion to organic farming: a multidimensional research object at the crossroads of agricultural and social sciences. Rev Agron Sustain Dev 29:97-112. doi:10.1051/ agro:2008007

Lichtfouse E, Navarrete M, Debaeke P, Souchère V, Alberola C, Ménassieu J (2009) Agronomy for sustainable agriculture. A review. Agron Sustain Dev 29:1-6. doi:10.1051/agro:2008054

Luhmann N (1989) 1986 Ecological Communication. Polity Press, Cambridge

Luhmann, N (1990) Essays on self-reference. New York: Colombia University Press

Luhmann N (1991) Operational closure and structural coupling: the differentiation of the legal system. Cardozo Law Rev 13:1419-1441

Luhmann N (1995) Social systems. Stanford University Press, Stanford

Luhmann N (2012) Theory of society, volume 1. Stanford University Press, Stanford

Luhmann N (2013a) Theory of society, volume 2. Stanford University Press, Stanford

Luhmann N (2013b) 2002, 1991-1992 Introduction to systems theory. Polity Press, Cambridge

Luttikholt L (2007) Principles of organic agriculture as formulated by the international federation of organic agriculture movements. Life Sci $54: 347-360$

Marsden T (2013) From post-productionism to reflexive governance: contested transitions in securing more sustainable food futures. J Rural Stud 29:123-134. doi:10.1016/j.jrurstud.2011.10.001

Maturana HR, Varela F (1980) Autopoiesis and cognition: the realization of the living. Reidel Publishing Company

Maturana H, Varela F (1981) Introductory remarks. In: Zeleny M (ed) Autopoiesis: a theory of living organization. North-Holland, New York, pp 18-19

Maturana HR, Varela F (1987) Tree of knowledge: biological roots of human understanding. Shambhala Publishers, Boston

Mc Donagh J (2014) Rural geography II: discourses of food and sustainable rural futures. Progress in Human Geography (in press). doi: 10 . $1177 / 0309132513514507$

Murphy J (2000) Ecological modernisation. Geoforum 31:1-8. doi:10. 1016/S0016-7185(99)00039-1

Noe E, Alrøe HF (2011) Quality, coherence and cooperation: a framework for studying the mediation of qualities in food networks and collective marketing strategies. Int J Sociol Agric Food 18(1):12-27

Noe E, Alrøe HF, Langvad AMS (2008) A polyocular framework for research on multifunctional farming and rural development. Sociol Rural 48:1-15. doi:10.1111/j.1467-9523.2008.00451.x

Noe E, Alrøe HF et al. (2014) Barriers for developing more robust organic arable farming systems: implementing research knowledge in practice and knowledge asymmetries. Submitted to Sociologia Ruralis

Pruzan P, Thyssen O (1994) The renaissance of ethics and the ethical accounting statement. Educ Technol 34(1):23-28

Qvortrup L (2003) The hypercomplex society. P. Lang Publishing Co., New York

Thompson PB (2007) Agricultural sustainability: what it is and what it is not. Int J Agric Sustain 5(1):5-16. doi:10.1080/14735903.2007. 9684809

Yamada S, Ruttan VW (1980) International Comparisons of Productivity in Agriculture. In: Kendrick JW, Vaccara BN (eds) New developments in productivity measurement. Univ. Chicago Press, pp. 507-594

Uexküll J von (1982) The theory of meaning. Semiotica 42(1): 25-82 